\title{
Assessment of Nocturnal Hypoventilation by Different Methods and Definitions in Children with Neuromuscular Disease: Oxycapnography and Blood Gas Analysis
}

\author{
Nöromusküler Hastalığı Olan Çocuklarda Kronik Ventilasyon \\ Bozukluğunun Oksikapnografi ve Kan Gazı Yöntemleriyle \\ Değerlendirilerek Karşılaştırılması
}

\section{Yetkin AYHAN $\odot$, Elif YUKSEL KARATOPRAK $\odot$, Zeynep Reyhan ONAY $\odot$, Sinem CAN OKSAY $\odot$, Saniye GIRIT $\odot$}

Ethics Committee Approval: This study was approved by the İstanbul Medeniyet University Training and Research Hospital Clinical Research Ethics Committee, 18 July 2018/0277. Conflict of interest: The authors declare that they have no conflict of interest.

Funding: None.

Informed Consent: Inform consent was not necessary because the design of study.
Cite as: Ayhan Y, Karatoprak EY, Onay ZR, Can Oksay S, Girit S. Assessment of nocturnal hypoventilation by different methods and definitions in children with neuromuscular disease: Oxycapnography and blood gas analysis. Medeni Med J. 2021;36:106-16.

\begin{abstract}
Objective: To investigate whether partial arterial carbon dioxide pressure $\left(\mathrm{PaCO}_{2}\right)$ level in arterial blood gas analysis that was used to predict nocturnal hypoventilation $(\mathrm{NH})$ is concordant with nocturnal end-tidal $\mathrm{CO}_{2}$ $\left(\mathrm{PetCO}_{2}\right)$ measurement obtained by a noninvasive method of oxycapnography in children with neuromuscular disease (NMD).

Methods: Twenty-one patients aged 6-18 years with a confirmed diagnosis of NMD were enrolled. Each patient underwent a nocturnal oxycapnography study using an orinasal probe and a pulse oximetry finger probe to record PetCO ${ }_{2}$, oxygen saturation $\left(\mathrm{SpO}_{2}\right)$, pulse rate, and respiratory rate. Arterial blood gas analysis was performed to record $\mathrm{PaCO}_{2}$ levels on three occasions at night (23:00 pm, 03:00 am, 07:00 am).

Results: The mean overnight PaCO ${ }_{2}$ level of the three blood gas analyses (mean PaCO ${ }_{2}$ noct) was $41.78 \pm 4.69$ mmHg. A significant change was observed between mean PaCO 23:00 and PaCO 07:00 levels ( $p=0.032$ ). There was no significant difference between $\mathrm{PaCO}_{2}, \mathrm{PetCO}_{2}$, and $\mathrm{SpO}_{2}$ levels in the $\mathrm{NMD}$ group. The interclass correlation coefficient between $\mathrm{PaCO}_{2}$ 07:00 and PetCO levels was 0.791 (95\% Cl: 0.533-0.923); the interclass correlation coefficient between overnight mean $\mathrm{PaCO}_{2}$ and PetCO levels was 0.811 (95\% Cl:0.533-0.923). Conclusion: Our study indicates that nocturnal PetCO, and $\mathrm{PaCO}_{2}$ levels were statistically comparable but the use of $\mathrm{PaCO}_{2}$ alone is not adequate to make an early diagnosis of $\mathrm{NH}$ in NMD. There is a need for making more restrictive definitions for $\mathrm{NH}$, and conducting studies with larger study populations to reach an agreement on the best definition of hypoventilation, and updating consensus guidelines.
\end{abstract}

Keywords: Neuromuscular disease, nocturnal hypoventilation, end-tidal $\mathrm{CO}_{2}$, partial arterial carbon dioxide pressure, oxycapnography

öz

Amaç: Nokturnal hipoventilasyonu (NH) tahmin etmek için arteriyel kan gazı analizinde parsiyel arteriyel karbondioksit basıncı $\left(\mathrm{PaCO}_{2}\right)$ ile invaziv olmayan bir yöntem olan oksikapnografi ile elde edilen nokturnal endtidal $\mathrm{CO}_{2}\left(\mathrm{PetCO}_{2}\right)$ ölçümünün birbiriyle uyumlu olup olmadığını araștırmak.

Yöntem: Doğrulanmış NMD tanısı olan 6-18 yaşları arasında 21 hasta kaydedildi. Her hasta, PetCO ${ }_{2}$, oksijen satürasyonu $\left(\mathrm{SpO}_{2}\right)$, nabız sayısı ve solunum hızını kaydetmek için bir orinasal prob ve bir nabız oksimetre parmak probu kullanılarak bir nokturnal oksikapnografi calısmasına tabi tutuldu. PaCO seviyelerini kaydetmek için gece üc kez (23:00 pm, 03:00 am, 07:00 am) arteriyel kan gazı analizi yapıldı.

Bulgular: Üç kan gazı analizinin ortalama gecelik $\mathrm{PaCO}_{2}$ seviyesi (ortalama $\mathrm{PaCO}_{2}$ noct) $41,78 \pm 4,69 \mathrm{mmHg}$ idi. Ortalama $\mathrm{PaCO}_{2}$ 23:00 ve PaCO 07 : 00 seviyeleri arasında anlamlı bir değişiklik gözlendi $(p=0,032)$. NMD grubunda $\mathrm{PaCO}_{2}$, PetCO 2 ve $\mathrm{SpO}_{2}$ seviyeleri arasında anlamlı bir fark yoktu. $\mathrm{PaCO}, 07: 00$ ve PetCO ${ }_{2}$ sonuçları arasındaki simiflar arası korelasyon katsayısı 0,791 (\%95 Cl: 0,533-0,923); Gecelik ortalama $\mathrm{PaCO}_{2}$ ve PetCO arasındaki sınıflar arası korelasyon katsayısı 0,811 (\%95 Cl: 0,533-0,923) idi.

Sonuc: Calışmamız, nokturnal $\mathrm{PetCO}_{2}$ ve $\mathrm{PaCO}_{2}$ düzeylerinin istatistiksel olarak karssılaștırılabilir olduğunu, ancak NMD'de NH'nin erken teşhisi için tek başına $\mathrm{PaCO}_{2}$ kullanımının yeterli olmadığını göstermektedir. NH için daha kısıtlayılı tanımlar yapmaya, hipoventilasyonun en iyi tanımı üzerinde bir anlassmaya varmak için daha geniş çalışma popülasyonları ile çalışmalar yürütmeye ve kılavuzları güncellemeye ihtiyaç vardır.

Anahtar kelimeler: Nöromüsküler hastalık, nokturnal hipoventilasyon, end-tidal $\mathrm{CO}_{2}$, parsiyel arteriyel karbondioksit basıncl, oksikapnografi
Received: 18 January 2021

Accepted: 24 April 2021

Online First: 18 June 2021

Corresponding Author:

S. Girit

ORCID: 0000-0001-7556-6568

Istanbul Medeniyet University Faculty of Medicine, Department of Pediatric Pulmonology, Istanbul, Turkey

saniyegirit@gmail.com

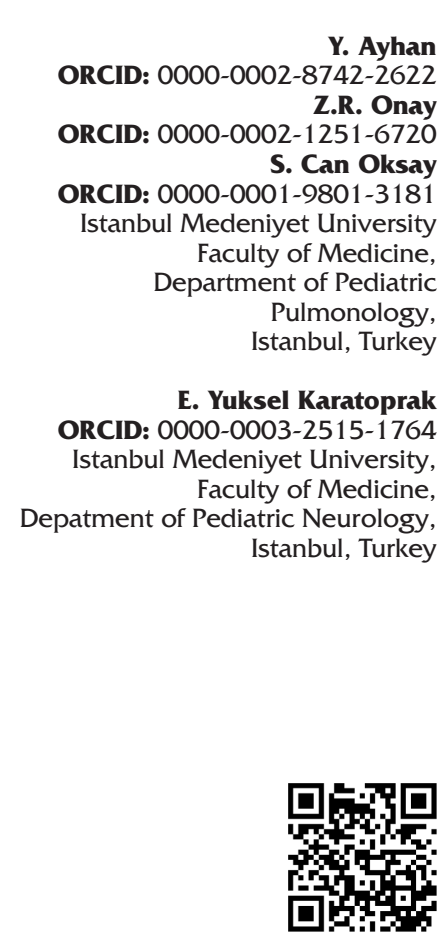


Y. Ayhan et al. Assessment of Nocturnal Hypoventilation by Different Methods and Definitions in Children with Neuromuscular Disease: Oxycapnography and Blood Gas Analysis

\section{INTRODUCTION}

Patients with neuromuscular disease (NMD) will not only experience parenchymal lung diseases such as recurrent pneumonia and atelectasis but also nocturnal sleep-disordered breathing disorders as their respiratory muscle weakness progresses $^{1}$. In this group of patients, respiratory system muscles are also affected in addition to skeletal muscles. Patients can avoid hypoxemia and hypercarbia via controlled hyperventilation when awake. In sleep, however, they become vulnerable to hypoventilation and hypercarbia associated with shallow ventilation and reduced tonus of upper respiratory tract and intercostal muscles. Neuromuscular weakness will worsen nocturnal respiratory problems in sleep, and thus will lead to hypercapnia and hypoxemia that frequently emerge at night before daytime ventilation disorders become evident ${ }^{2}$.

In children with $\mathrm{NMD}$, the prevalence of sleep-disordered breathing (SDB) disorders (hypoventilation, hypoxemia, central orobstructive apnea-hypopnea) was reported as high as 30$70 \%{ }^{3,4}$. As there is no large-scale studies, the incidence varies by different study centers, children's age range, NMD type, the diagnostic method used, and even differing criteria used in the diagnostic methods.

As symptoms and signs alone are not sufficiently reliable for diagnosing sleep-disordered breathing (SDB) and as polysomnography (PSG) has limited practicality and availability, various researchers have thought various alternative diurnal and nocturnal screening tests to predict SDB. Furthermore, daytime respiratory function tests do not reliably identify patients with SDB in the absence of hypercapnia ${ }^{5,6}$. Thus, screening tests are needed to diagnose SDB before the development of signs of daytime hypercapnia among children with neuromuscular weakness.

Although in the literature PSG is considered the gold standard test for diagnosing and classifying SDB and determining its severity, there is an ongoing debate as to whether or not routine monitoring of the $\mathrm{CO}_{2}$ level is performed in most sleep laboratories. Therefore, $\mathrm{CO}_{2}$ measurements have been recommended as a marker of airway obstruction and quantitative measurement of alveolar hypoventilation in all children ${ }^{7,8}$. However, there has been no consensus yet on a validated definition of nocturnal hypoventilation (NH) in children. A study where PSG, transcutaneous $\mathrm{CO}_{2}$ $\left(\mathrm{PtcCO}_{2}\right)$, and end-tidal $\mathrm{CO}_{2}\left(\mathrm{PetCO}_{2}\right)$ levels were compared in 609 patients, mean $\mathrm{PtcCO}_{2}$ was found above $50 \mathrm{mmHg}$ in $11.9 \%$ of 318 patients who had an apnea-hypopnea index (AHI) below 59 . Additionally, nocturnal $\mathrm{PtcCO}_{2}$ level was found to increase independently of the severity of the obstructive sleep apnea (OSA) due to respiratory muscle hypotonicity among children with Down syndrome ${ }^{10}$. Hence, as polysomnography is not readily available for children in our country and as increased $\mathrm{PCO}_{2}$ levelsaredetectableindependently of $\mathrm{AHI}, \mathrm{NH}$ screening using a simpler method will be more practical and feasible.

Capnography is a noninvasive method that enables continuous monitoring of a patient's ventilatory status ${ }^{11}$. We hope that it will guide us in early diagnosis and management. Hence, we performed an overnight recording and analysis of end-tidal carbon dioxide $\left(\mathrm{PetCO}_{2}\right)$ level and measured oxygen saturation $\left(\mathrm{SpO}_{2}\right)$ in combination with respiratory and pulse rates using an oxycapnography device in order to screen nocturnal breathing disorders (hypercarbia, hypoxia). So far, we used to check the $\mathrm{PaCO}_{2}$ level to predict nocturnal hypoventilation by performing blood gas analyses at our clinic (on three occasions: 23:00 pm, 03:00 am, and 07:00 am). Our objective was to investigate whether $\mathrm{PaCO}_{2}$ levels in blood gas analysis we use to predict hypoventilation and nocturnal $\mathrm{PetCO}_{2}$ levels measured using the noninvasive method of oxycapnography would show concordance in children with NMD. The literature review revealed that these two methods were compared in 
healthy subjects and different patient groups but they were not used to screen sleep-disordered breathing in children with NMD. As there is no confirmed $\mathrm{NH}$ level associated with end-organ damage in children, we made the comparison in accordance with the American Academy of Sleep Medicine (AASM) 2019 criteria and at lower $\mathrm{CO}_{2}$ levels. We assessed hypoventilation by different "hypercarbia" levels and "nocturnal hypercarbia indexes".

\section{MATERIAL and METHODS}

Patients: This study enrolled 21 patients aged 6-18 years who were followed up at Istanbul Medeniyet University Pediatric Neurology outpatient clinic with genetically confirmed diagnosis of pediatriconset NMD. Oxycapnography was performed on patients between April 2018 and December 2018. Parents of all patients gave their written informed consent for participation in the study by signing the "informed consent form for study participation". The local ethics committee of our hospital approved the study with a report number of $2018 / 0277$.

Patients with signs of acute respiratory failure, acute pulmonary parenchymal disease (pneumonia, bronchitis, etc.), primary congenital heart disease, and chronic lung disease were excluded. Patients in the early onset muscle disease group like spinal muscular atrophy were also excluded. Patients with any of the following conditions including "adenoidtonsil hypertrophy, micrognathia, macroglossia, septal deviation, or nasal deformity" that could cause elevated $\mathrm{CO}_{2}$ levels via "mechanical upper airway obstruction" apart from the primary disease detected in physical examination were also excluded. Patients were questioned about signs or symptoms likely indicating hypercarbia and hypoxia, such as snoring, restless sleep, waking up suddenly, morning dizziness, and morning headache, and those with any of these conditions were excluded. Thus, by recruiting patients without primary pulmonary parenchymal disease, mechanical causes of OSA, and clinical signs of nocturnal hypoventilation, we had the opportunity to assess nocturnal hypercarbia and hypoxia using two different methods at the earliest stage of the disease.

\section{Method}

A spirometric assessment was performed using the Spirolab III Color LCD device in patients who could cooperate with the research team. The study data were recorded on a computer using the WinspiroPRO 6,8 software that was compatible with the device. Spirometry was performed by a trained and experienced a nurse working at the respiratory function test (RFT) unit and in accordance with the recommendations made by the European Respiratory Society and American Thoracic Society ${ }^{12,13}$. Forced expiratory volume measured in the first second of exhalation after maximal inspiration (FEV1), forced vital capacity (FVC), and $25-75 \%$ volume capacity of exhalation (FEF25-75) were recorded. FEV1/FVC ratio was documented. The spirometric measurements were analyzed and interpreted in accordance with the guidelines of the above-mentioned societies $^{12,13}$. Then, the patients were monitored during an overnight stay at the Pediatric Chest Diseases Department. Blood samples were taken via radial artery puncture for blood gas analysis to record the $\mathrm{PaCO}_{2}$ level at 11:00 pm, 03:00 am, and 07:00 am. The patients were connected to an oxycapnography device with a pediatric $\mathrm{CO}_{2} \mathrm{Oral} /$ Nasal sampling set between 11:00 pm and 07:00 am, and pulse oximetry monitoring was performed using fingertip type pediatric probes. The capnography device was calibrated every 24 hours as recommended by the manufacturer. PetCO $\mathrm{CPO}_{2}$, pulse rate, and respiratory rate were measured every second by the oxycapnography device and saved in the device memory. The recorded data were transferred to the Excel (TM) software in the morning and were then analyzed in the computer. The mean $\mathrm{PetCO}_{2}$ level, the mean level and duration (hypercarbia time) of 
Y. Ayhan et al. Assessment of Nocturnal Hypoventilation by Different Methods and Definitions in Children with Neuromuscular Disease: Oxycapnography and Blood Gas Analysis

PetCO ${ }_{2}$ levels of $\geq 50 \mathrm{mmHg}$, and the mean level and duration (hypoxia time) of $\mathrm{SpO}_{2}$ readings below 90\% were recorded. The "nocturnal hypercarbia index" and "nocturnal hypoxia index" were calculated by dividing the total recording time by hypercarbia time and hypoxemia time, respectively. Then, the correlation between the $\mathrm{PaCO}_{2}$ level measured in three blood gas analyses and the nocturnal PetCO $\mathrm{P}_{2}$ levels were analyzed.

\section{Definitions}

Nocturnal Hypercarbia: Defined as the mean PetCO level $\geq 50 \mathrm{mmHg}$ or mean $\mathrm{PaCO}_{2}$ level $\geq 45 \mathrm{mmHg}$ for greater than $2 \%$ of the total recording time ${ }^{14,15}$.

Nocturnal Hypoxia: Defined as the mean $\mathrm{SpO}_{2}$ level being below $90 \%$ for greater than $2 \%$ of the total recording time ${ }^{16}$.

Nocturnal Hypoventilation: Defined as $\mathrm{PetCO}_{2}$ level $\geq 50 \mathrm{mmHg}$ for greater than $25 \%$ of the total recording time or $\mathrm{SpO}_{2}$ level below $90 \%$ for greater than $10 \%$ of the total recording time ${ }^{14-16}$.

Nocturnal Hypercarbia Index: Defined as the ratio of the recording time showing hypercarbia on oxycapnography to the total recording time.

Nocturnal Hypoxia Index: Defined as the ratio of the recording time showing hypoxia on oxycapnography to the total recording time.

Night Arterial Blood Gases: According to routine clinical practice in the unit, nocturnal blood gas levels were measured at 11:00 pm as well as at 03:00 am and 07:00 am. Blood samples were drawn at rest and immediately carried in an ice bag to the central hospital laboratory for analysis.

Oxycapnograph: The Capnostream ${ }^{\mathrm{TM}} 35$ Portable Respiratory Monitor PM35MN, with Microstream ${ }^{\mathrm{TM}}$ $\mathrm{EtCO}_{2}$ and Nellcor ${ }^{\mathrm{TM}} \mathrm{SPO}_{2}$ Technologies, is a portable bedside monitor that continuously monitors:

- End-tidal carbon dioxide $\left(\mathrm{PetCO}_{2}\right)$-level of carbon dioxide in exhaled breath $\left(\mathrm{CO}_{2}\right.$ Oral/Nasal sampling set)

- Respiratory rate (RR)

- Oxygen saturation $\left(\mathrm{SpO}_{2}\right)$

- Pulse rate (PR)

\section{Statistical Analysis}

The statistical analyses of this study were performed using NCSS (Number Cruncher Statistical System) 2007 Statistical Software Package (Utah, USA). In addition to descriptive statistical methods (mean and standard deviation), temporal comparison of normally distributed variables was performed with simple repeated measures analysis of variance; subgroup comparisons with Newman-Keuls multiple comparison tests; independent group comparisons with one-way analysis of variance (ANOVA); dependent group comparisons with paired samples t-test; independent group comparisons of non-normally distributed variables with Kruskal Wallis test; independent two group comparisons with Mann Whitney-U test; the relations between qualitative variables with Chisquare test; and inter-variable correlations with Pearson's correlation test. Bland \&Altman test and interclass correlation coefficient were used to test agreement between mean end-tidal $\mathrm{CO}_{2}$, mean $\mathrm{PaCO}_{2}$ 23:00, and mean $\mathrm{PaCO}_{2}$ 07:00. The results were analyzed at the significance level of $\mathrm{p}<0.05$.

\section{RESULTS}

After patients with NMD were evaluated, Twentynine out of 50 NDM patients who did not meet the inclusion criteria were excluded from the study (Figure 1). The mean age of the study population including $17(81 \%)$ and $4(19 \%)$ female patients was $10.55 \pm 5$ (6-16) years. The mean Body Mass Index (BMI) was $15.95 \pm 3.76 \mathrm{~kg} / \mathrm{m}^{2}$. BMI percentile was $<5$ in 11 (52.38\%), 25-50 in 5 (23.81\%), and higher than 50 in 5 patients.

The mean duration of NMD follow-up was $4.38 \pm 3.32$ years. The distribution of NMDs was as follows: congenital muscular disease (n:16 including 10 patients with Duchenne or Becker muscular dystrophy (DMD-BMD), one patient with facioscapulohumeral muscular dystrophy (FSHMD), one patient with limb-girdle muscular dystrophy (LGMD), four patients with congenital 


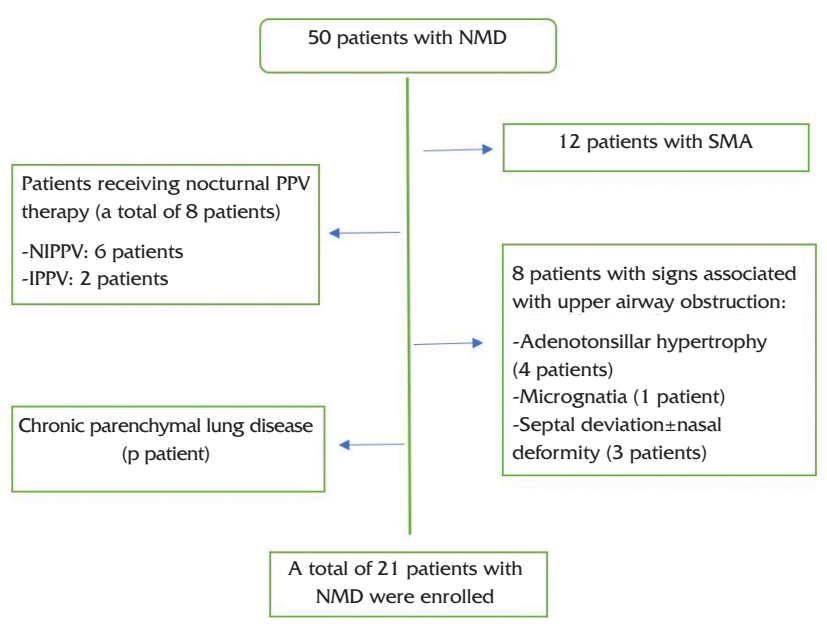

Figure 1. After patients with NMD were evaluated, 29 patients of a total of 50 patients were excluded due to not having met the inclusion criteria, and the remaining 21 patients were enrolled.

myopathy), and five patients had hereditary polyneuropathy (hereditary motor-sensory neuropathy (HMSN)).

Spirometry test results of $14(66.67 \%)$ patients were as follows: mean $\mathrm{FEV}_{1} \%, 78.09 \pm 27.72$ ); mean FVC\%, 73.09 \pm 23 ; mean FEV $_{1} / \mathrm{FVC}, 101.18 \pm 12.87$. As comorbidities gastroesophageal reflux disease was seen in one (4.76\%) and scoliosis in six (28.57\%) patients. The patients with thoracic scoliosis had a significantly lower mean $\mathrm{SpO}_{2}$ level compared to those without $(p=0.019)$.

Mean values of parameters determined in blood gas analysis were as follows: $\mathrm{PaCO}_{2}$ at $11: 00$ pm ( $\mathrm{PaCO}_{2}$ 23:00): 40.28 $\pm 5.37 \mathrm{mmHg} ; \mathrm{PaCO}_{2}$ at 03:00: 42.13 $\pm 4.39 \mathrm{mmHg} ; \mathrm{PaCO}_{2}$ 07:00: $42.93 \pm 6.67 \mathrm{mmHg}$, and finally $\mathrm{PaCO}_{2}$ noc: $41.78 \pm 4.69 \mathrm{mmHg}$ which is the mean value of the three nocturnal blood gas $\mathrm{PaCO} 2$ levels. A significant change was observed between the mean $\mathrm{PaCO}_{2}$ 23:00, $\mathrm{PaCO}_{2}$ 03:00, and $\mathrm{PaCO}_{2}$ 07:00 ( $p=0.032$ ). The mean $\mathrm{PaCO}_{2}$ 23:00 level was significantly lower than mean $\mathrm{PaCO}_{2}$ 03:00 and mean $\mathrm{PaCO}_{2}$ 07:00 levels ( $\mathrm{p}=0.042, \mathrm{p}=0.032$; the mean $\mathrm{PaCO}_{2}$ 03:00 and mean $\mathrm{PaCO}_{2}$ 07:00 levels were statistically comparable $(p=0.550)$. Oxycapnography recording data were presented in Table I.
Table 1. Oxycapnography data of patients with NMD.

\begin{tabular}{|c|c|c|c|}
\hline Oxycapnography Data & $\mathbf{n}$ & Mean \pm SD & Median (IQR) \\
\hline $\begin{array}{l}\text { Total recording time } \\
\text { (hours) }\end{array}$ & 21 & 7 & 7.8 \\
\hline Mean $\mathrm{PetCO}_{2}$ & 21 & 37 & 38.3 \\
\hline Maximum PetCO & 21 & $47.67 \pm 3.04$ & $47(45.5-49.5)$ \\
\hline Mean PetCO $>45^{2} \mathrm{mmHg}$ & 17 & $45.82 \pm 0.55$ & $45.9(45.4-46.1)$ \\
\hline $\begin{array}{l}\text { Nocturnal Hypercarbia } \\
\text { index (\%) }\end{array}$ & 17 & $5.02 \pm 12.69$ & $0.7(0.26-3.2)$ \\
\hline Mean & 21 & 97 & $97.6(97$ \\
\hline $\mathrm{SpO}_{2}$ & 21 & $84.62 \pm 6.98$ & $86(79.5-91)$ \\
\hline$<90^{2}$ & 13 & $85.27 \pm 3.12$ & $86.1(85.4-87)$ \\
\hline $\begin{array}{l}\text { Nocturnal hypoxia index } \\
\text { (\%) }\end{array}$ & 13 & $0.84 \pm 1.97$ & $0.1(0.06-0.415)$ \\
\hline
\end{tabular}

PetCO ${ }_{2}$ : end-tidal $\mathrm{CO}_{2}$ partial pressure, $\mathrm{SpO}_{2}$ : oxygen saturation

There were significant differences between $\mathrm{PaCO}_{2}$ results and $\mathrm{PetCO}_{2}$ and $\mathrm{SpO}_{2}$ recordings obtained in muscular dystrophy (MD) (n:12), myopathy $(n: 4)$ and polyneuropathy ( $n: 5)$ groups ( $p>0.05)$. Tables 2 and 3 shows the duration of the primary disease, BMI, and pulmonary function test results, and the correlation between blood gas analysis and oxycapnography recordings of the patients in the whole study population and the muscular dystrophy group. The correlation between $\mathrm{PaCO}_{2}$ level in blood gas analysis and $\mathrm{PetCO}_{2}$ level measured by oxycapnography was shown in Tables 4 and 5 . We may state that there is a concordance between $\mathrm{PaCO}_{2}$ and PetCO levels. However, the intraclass correlation coefficient is slightly above the upper limit of normal, and 95\% CI was slightly wider than we expected.

We had no patient with a $\mathrm{PaCO}_{2}$ level above 45 $\mathrm{mmHg}$ at 23:00 pm. $\mathrm{PaCO}_{2}$ levels were above $45 \mathrm{mmHg}$ at 03:00 am in 6; and at 07:00 am in 5 patients; and three patients had a $\mathrm{PaCO}_{2}$ level above $50 \mathrm{mmHg}$. Two of our patients although their $\mathrm{PaCO}_{2}$ levels were below $45 \mathrm{mmHg}$ at 07:00 am (Patient No.17 and 18) met the oxycapnographic criteria of nocturnal hypoventilation ie. one of them had hypercarbia and the other hypoxia. In contrast, one of the two patients with a $\mathrm{PaCO}_{2}$ level above $50 \mathrm{mmHg}$ at 07:00 am had normal oxycapnography levels while the other had nocturnal hypercarbia. Two of the five patients 
Y. Ayhan et al. Assessment of Nocturnal Hypoventilation by Different Methods and Definitions in Children with Neuromuscular Disease: Oxycapnography and Blood Gas Analysis

Table 2. Hypercarbia and hypoxemia status and the relationship between pulmonary function tests and other clinical conditions of the patients with NMD.

\begin{tabular}{|c|c|c|c|c|c|c|}
\hline & & Disease Duration & BMI & FEV $_{1}$ & FVC & FEV $_{1} /$ FVC \\
\hline \multirow[t]{2}{*}{ Mean $\mathrm{PetCO}_{2}$} & $\mathrm{r}$ & -0.189 & 0.473 & 0.441 & 0.311 & 0.657 \\
\hline & $\mathrm{p}$ & 0.412 & 0.03 & 0.175 & 0.352 & 0.028 \\
\hline \multirow[t]{2}{*}{ Maximum $\mathrm{PetCO}_{2}$} & $\mathrm{r}$ & 0.018 & -0.022 & -0.205 & -0.374 & 0.348 \\
\hline & $\mathrm{p}$ & 0.938 & 0.926 & 0.546 & 0.257 & 0.295 \\
\hline \multirow{2}{*}{ Mean $\mathrm{PetCO}_{2}>45 \mathrm{mmHg}$} & $\mathrm{r}$ & -0.069 & 0.099 & -0.024 & -0.164 & 0.005 \\
\hline & $\mathrm{p}$ & 0.792 & 0.705 & 0.951 & 0.673 & 0.991 \\
\hline \multirow[t]{2}{*}{ Nocturnal Hypercarbia index (\%) } & $\mathrm{r}$ & -0.106 & 0.190 & 0.213 & 0.124 & 0.582 \\
\hline & $\mathrm{p}$ & 0.686 & 0.466 & 0.583 & 0.751 & 0.100 \\
\hline \multirow{2}{*}{ Minimum $\mathrm{SpO}_{2}$} & $\mathrm{r}$ & -0.247 & 0.206 & 0.396 & 0.285 & 0.781 \\
\hline & $\mathrm{p}$ & 0.281 & 0.372 & 0.228 & 0.395 & 0.005 \\
\hline \multirow[t]{2}{*}{ Mean $\mathrm{SpO}_{2}<90$} & $\mathrm{r}$ & 0.127 & 0.028 & -0.233 & -0.111 & 0.06 \\
\hline & $p$ & 0.68 & 0.927 & 0.615 & 0.813 & 0.898 \\
\hline \multirow[t]{2}{*}{ Overall mean $\mathrm{SpO}_{2}$} & $r$ & -0.315 & 0.292 & 0.391 & 0.304 & 0.553 \\
\hline & $\mathrm{p}$ & 0.165 & 0.198 & 0.235 & 0.364 & 0.078 \\
\hline \multirow{2}{*}{ Overnight Blood Gas mean $\mathrm{PaCO}_{2}$} & $\mathrm{r}$ & -0.338 & 0.220 & 0.025 & -0.044 & -0.066 \\
\hline & $\mathrm{p}$ & 0.134 & 0.339 & 0.943 & 0.899 & 0.847 \\
\hline
\end{tabular}

Pearson Correlation

PetCO ${ }_{2}$ : end-tidal $\mathrm{CO}_{2}$ partial pressure, $\mathrm{SpO}_{2}$ : oxygen saturation, $\mathrm{PaCO}_{2}$ : partial carbon dioxide pressure, BMI: Body mass index, $F E V_{1}$ : Forced expiratory volume in one second, FVC: forced vital capacity.

Table 3. Hypercarbia and hypoxemia status and the relationship between pulmonary function tests and other clinical conditions of the patients with Muscular Dystrophy.

\begin{tabular}{|c|c|c|c|c|c|c|}
\hline & & Disease Duration & BMI & FEV $_{1}$ & FVC & FEV $_{1} /$ FVC \\
\hline \multirow[t]{2}{*}{ Mean $\mathrm{PetCO}_{2}$} & $\mathrm{r}$ & -0.147 & 0.417 & 0.521 & 0.391 & 0.758 \\
\hline & $p$ & 0.648 & 0.178 & 0.368 & 0.515 & 0.137 \\
\hline \multirow{2}{*}{ Maximum $\mathrm{PetCO}_{2}$} & $\mathrm{r}$ & 0.053 & -0.201 & -0.298 & -0.384 & -0.06 \\
\hline & $p$ & 0.871 & 0.531 & 0.626 & 0.524 & 0.924 \\
\hline \multirow[t]{2}{*}{ Mean $\mathrm{PetCO}_{2}>45 \mathrm{mmHg}$} & $\mathrm{r}$ & 0.055 & -0.176 & -0.673 & -0.689 & -0.560 \\
\hline & p & 0.888 & 0.650 & 0.027 & 0.011 & 0.440 \\
\hline \multirow[t]{2}{*}{ Nocturnal Hypercarbia index (\%) } & $\mathrm{r}$ & -0.345 & 0.139 & 0.814 & 0.851 & 0.323 \\
\hline & $\mathrm{p}$ & 0.363 & 0.722 & 0.186 & 0.149 & 0.677 \\
\hline \multirow[t]{2}{*}{ Minimum $\mathrm{SpO}_{2}$} & $\mathrm{r}$ & -0.636 & 0.507 & 0.815 & 0.719 & 0.639 \\
\hline & $\mathrm{p}$ & 0.026 & 0.092 & 0.093 & 0.171 & 0.018 \\
\hline \multirow[t]{2}{*}{ Mean $\mathrm{SpO}_{2}<90$} & $\mathrm{r}$ & 0.106 & 0.407 & 0.400 & 0.212 & 0.973 \\
\hline & $p$ & 0.842 & 0.423 & 0.738 & 0.864 & 0.147 \\
\hline \multirow[t]{2}{*}{ Overall mean $\mathrm{SpO}_{2}$} & $\mathrm{r}$ & -0.325 & 0.245 & 0.285 & 0.179 & 0.841 \\
\hline & $\mathrm{p}$ & 0.303 & 0.443 & 0.643 & 0.773 & 0.074 \\
\hline \multirow[t]{2}{*}{ Overnight Blood Gas mean $\mathrm{PaCO}_{2}$} & $\mathrm{r}$ & -0.068 & 0.041 & -0.068 & -0.143 & 0.002 \\
\hline & $p$ & 0.833 & 0.900 & 0.913 & 0.819 & 0.998 \\
\hline
\end{tabular}

Pearson Correlation

PetCO $\mathrm{C}_{2}$ end-tidal $\mathrm{CO}_{2}$ partial pressure, $\mathrm{SpO}_{2}$ : oxygen saturation, $\mathrm{PaCO}_{2}$ : partial carbon dioxide pressure, $\mathrm{BMI}$ : Body mass index, $F E V_{1}$ : Forced expiratory volume in one second, FVC: forced vital capacity.

with a $\mathrm{PaCO}_{2}$ level above $45 \mathrm{mmHg}$ at 07:00 am had nocturnal hypercarbia; only one of the three patients with a $\mathrm{PaCO}_{2}$ level above $50 \mathrm{mmHg}$ had nocturnal hypercarbia.

We detected nocturnal gas exchange problems in a total of seven (33\%) patients including nocturnal hypercarbia in 5 and nocturnal hypoxia in 2 patients. According to the AASM criteria, only two $(9.5 \%)$ of our patients met the criteria for nocturnal hypoventilation.

\section{DISCUSSION}

We performed screening tests to reflect strictly early signs of SDB in a patient group free of any 
Table 4. Oxycapnography data of patients with NMD.

\begin{tabular}{|c|c|c|c|}
\hline & & $\mathrm{PaCO}_{2}{ }^{07: 00}$ & $\begin{array}{l}\text { Overnight Blood } \\
\text { Gas mean } \mathrm{PaCO}_{2}\end{array}$ \\
\hline \multirow[t]{2}{*}{ Mean $\mathrm{PetCO}_{2}$} & $\mathrm{r}$ & 0.713 & 0.678 \\
\hline & $\mathrm{p}$ & 0.003 & 0.007 \\
\hline \multirow[t]{2}{*}{ Maximum $\mathrm{PetCO}_{2}$} & $\mathrm{r}$ & 0.409 & 0.418 \\
\hline & $p$ & 0.066 & 0.059 \\
\hline \multirow[t]{2}{*}{ Mean $\mathrm{PetCO}_{2}>45 \mathrm{mmHg}$} & r & 0.02 & 0.097 \\
\hline & $\mathrm{p}$ & 0.939 & 0.710 \\
\hline
\end{tabular}

Pearson Correlation

\begin{tabular}{|c|c|c|}
\hline Mean $\mathrm{PetCO}_{2}$ & $\begin{array}{l}\text { Intra-class } \\
\text { correlation } \\
\text { Coefficient }\end{array}$ & $\begin{array}{l}95 \% \text { Confidence } \\
\text { Interval }\end{array}$ \\
\hline $\begin{array}{l}\mathrm{PaCO}_{2}{ }_{2}^{07: 00} \\
\text { Overnight Blood Gas mean } \\
\mathrm{PaCO}_{2}\end{array}$ & $\begin{array}{l}0.791 \\
0.811\end{array}$ & $\begin{array}{l}0.517-0.843 \\
0.533-0.923\end{array}$ \\
\hline
\end{tabular}

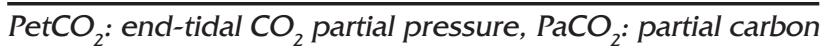
dioxide pressure.

signs or symptoms of nocturnal hypoventilation in which we eliminated the likelihood of any mechanical upper airway obstruction contributing to a respiratory disorder. We observed nocturnal hypercarbia in oxycapnography monitoring in about one third of our patients. $\mathrm{PaCO}_{2}$ and $\mathrm{PetCO}_{2}$ levels shown by oxycapnography and blood gas analysis were statistically concordant. However, our intraclass correlation coefficient was slightly above the upper limit of normal. The $95 \% \mathrm{Cl}$ and SD values, which we expected to be closer to each other, were also slightly wider. We believe that we would have attained more realistic results when we had separately analyzed the diagnostic groups within themselves and run the study with a larger number of patients.

Whereas $\mathrm{NH}$ was detected in only $9.5 \%$ of our patients according to the internationally recognized AASM criteria. While the proportion of patients with signs suggesting a nocturnal respiratory disorder rose to $33 \%$ when other data were also taken into account. Although our "nocturnal hypercarbia and hypoxia" definitions based on capnography results did not indicate a need for noninvasive mechanical ventilation treatment in the face of current treatment guidelines, they nevertheless indicated that one third of our patients were in a high-risk group necessitating close follow-up.

Arterial blood gas analysis is the gold standard test for assessing $\mathrm{PaCO}_{2}$ levels. However, it is not regarded as an appropriate screening test considering its painful and invasive nature, as well as the need for continuous catheterization ${ }^{17}$. Various techniques for noninvasive $\mathrm{CO}_{2}$ level monitoring have been tested in different patient populations for diagnostic efficacy since their introduction into clinical practice. Takano et al. ${ }^{18}$ reported that $\mathrm{PetCO}_{2}$ and $\mathrm{PaCO}_{2}$ were correlated in spontaneously breathing adults with the chronic parenchymal pulmonary disease; however, they still recommended the combined use of both methods. A study of 129 patients connected to a mechanical ventilator for any cause at a pediatric intensive care unit showed that PetCO ${ }_{2}$ monitoring may be recommended for the assessment of ventilation in patients with the mild-to-moderate pulmonary parenchymal disease. Nevertheless, the authors of the same study also stressed that the concordance between $\mathrm{PetCO}_{2}$ and $\mathrm{PaCO}_{2}$ was not strong enough among patients with severe parenchymal problems, for whom they argued blood gas analysis should continue to be the primary determinant of ventilatory efficiency ${ }^{19}$.

Another study that enrolled patients admitted to the intensive care unit for neurological problems suggested that $\mathrm{PetCO}_{2}$ monitorization could be used to monitor ventilation and hemodynamic status of critically ill patients with neurological problems although taking at least one blood gas sample at the beginning of monitorization would be also appropriate ${ }^{20}$. We solely enrolled asymptomatic children with NMD. We screened sleep-disordered breathing using both $\mathrm{PaCO}_{2}$ and PetCO ${ }_{2}$ levels. We found a significant correlation between $\mathrm{PaCO}_{2}$ levels measured at 03:00 am or 07:00 am and the PetCO $\mathrm{C}_{2}$ levels. But our intraclass correlation coefficient was slightly above the upper limit of normal. Additionally, we noted a slightly wider $95 \% \mathrm{CI}$ and SD ranges than we expected. 


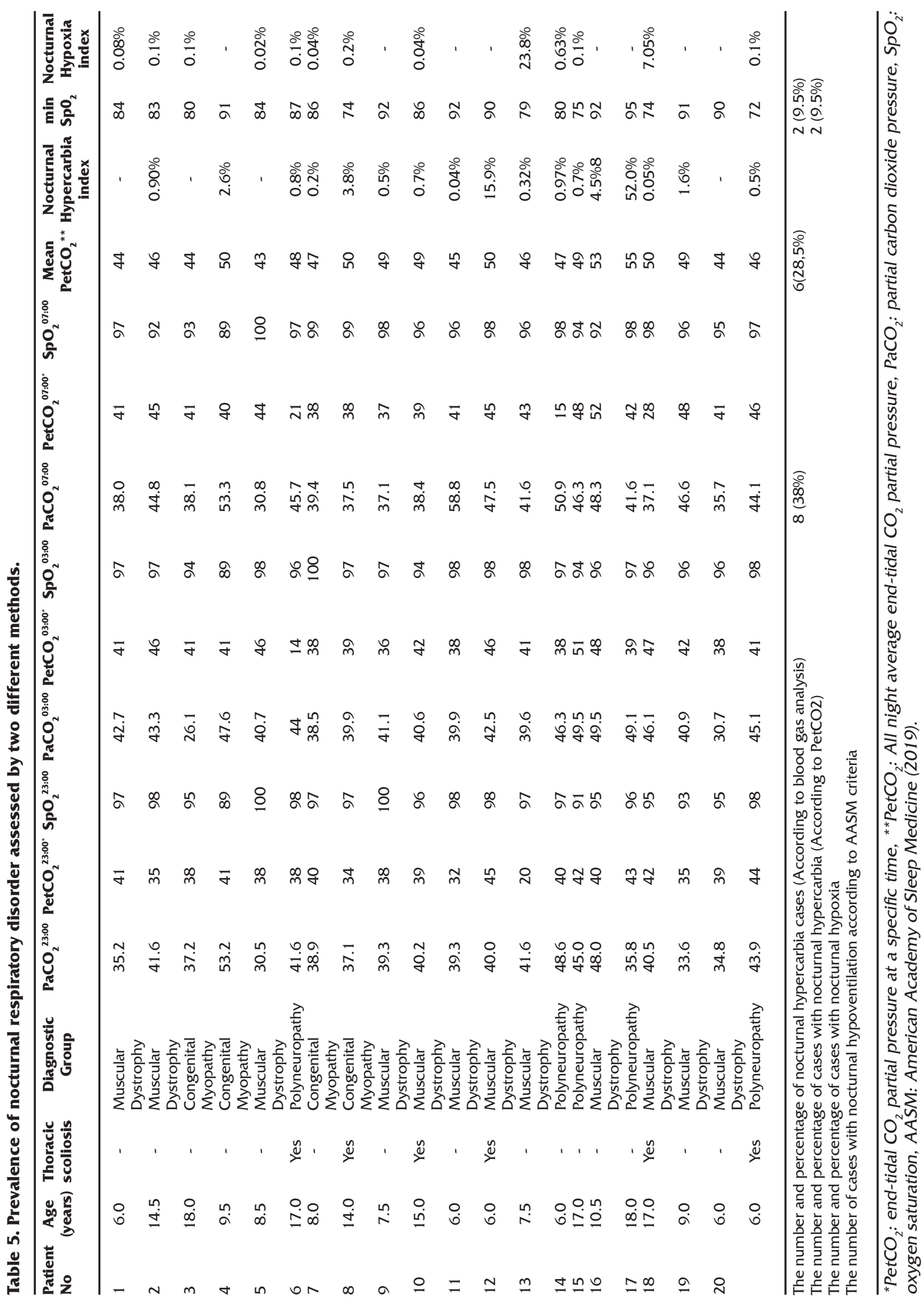


We believe that we would have attained more realistic results when we had separately analyzed the diagnostic groups within themselves and run the study with a larger number of patients. Although SDB is common among children with NMD, it is dificult to predict its time of onset. Thus, SDB can be screened with capnography, a noninvasive method, when longer follow-up periods are typically needed.

Among children with NMD, PFTs are particularly known for being the best determinant of nocturnal hypoventilation. In a study of 19 patients with DMD, FEV1 level below $40 \%$ was found to be a sensitive $(91 \%)$ but a nonspecific predictor of $\mathrm{SDB}^{21}$. Another prospective study reported that a drop in inspiratory vital capacity (IVC) to $60 \%$ may be a predictive criterion for the onset of nocturnal hypoventilation ${ }^{22}$. A drop of IVC ratio to $40 \%$, on the other hand, was proposed as a better indicator of nocturnal hypoventilation ${ }^{23}$. However, several other studies contradicted these findings. In a study of 52 children with NMD in whom overnight capnography monitoring, daytime blood gas analysis, and PFT was performed, 22 patients were found to have nocturnal hypercarbia $\left(\mathrm{PtcCO}_{2}>50\right.$ for greater than $2 \%$ of the recording) and 20 patients nocturnal hypoxemia $\left(\mathrm{SpO}_{2}<90\right.$ for greater than $2 \%$ of the recording); additionally, there was a correlation between FVC and nocturnal $\mathrm{SpO}_{2}$. However, that study failed to show any correlation between daytime pulmonary function tests and nocturnal $\mathrm{PetCO}_{2}{ }^{24}$. On the other hand, there was a correlation between $\mathrm{PetCO}_{2}$ and $\mathrm{SpO}_{2}$ and $\mathrm{FEV}_{1} / \mathrm{FVC}$ when the entire group of patients with NMD was analyzed in our study. However, when we analyzed the muscular dystrophy patients separately, we noted a negative correlation between $\mathrm{FEV}_{1}, \mathrm{FVC}$, and PetCO ${ }_{2}$, and a correlation between $\mathrm{FEV}_{1} / \mathrm{FVC}$ and min $\mathrm{SpO}_{2}$. We had only three patients with $\mathrm{FEV}_{1}$ and FVC levels below 60\%, of whom only one had nocturnal hypercarbia. All of the remaining patients had $\mathrm{FEV}_{1}$ and FVC levels as expected. In agreement with the preceding study, we showed a statistically significant correlation between $\mathrm{FEV}_{1} /$ FVC and $\min \mathrm{SpO}_{2}$.

Although we statistically showed that $\mathrm{PetCO}_{2}$ increased as $\mathrm{FEV}_{1}$ and FVC levels were reduced in the muscular dystrophy group, we could not ascertain the statistical relevance of this finding since basal pulmonary function levels were not much lower than expected. Spirometric pulmonary function test results such as FVC and $\mathrm{FEV}_{1}$ are highly correlated to nocturnal hypoventilation in adults with NMD, but it can not show such a correlation in children who have limited ability to complete pulmonary function tests ${ }^{25}$.

Kyphoscoliosis is a common comorbidity in patients with NMD. It contributes to an ineffective respiratory pump during expansion of the chest by creating a mechanical restraint around costovertebral joints ${ }^{26}$. It is particularly known to cause reductions in vital capacity as high as $20 \%$, which is further increased by the use of corsets to manage scoliosis ${ }^{27}$. We detected nocturnal hypercarbia in only two of our six patients with thoracic scoliosis, and we found no difference between patients with and without thoracic scoliosis with respect to spirometric pulmonary function test results. Our small sample size may indicate that our data on thoraco-scoliosis may not be reliable.

When sleep-disordered breathing in children is categorized into two main groups as OSA and nocturnal hypoventilation, polysomnography, and screening tests that can reveal nocturnal hypercarbia and hypoxemia come to one's mind. As polysomnography has remained hardly accessible in clinical practice for years, and even episodes of hypercarbia discordant with the AHI index are detectable, other screening tests have gradually begun to be prioritized ${ }^{4}$. Kirk et al. ${ }^{9}$ measured PSG and PetCO levels of 609 pediatric patients and found clinically significant increase, $\mathrm{PetCO}_{2}$ in $12 \%$ of patients with a low apneahypopnea index. A weak correlation between hypoventilation and $\mathrm{AHI}$ suggests that monitoring 
Y. Ayhan et al. Assessment of Nocturnal Hypoventilation by Different Methods and Definitions in Children with Neuromuscular Disease: Oxycapnography and Blood Gas Analysis

$\mathrm{CO}_{2}$ levels may prove predictive for SDB.

Depending on the screening test performed and the accepted $\mathrm{NH}$ definition, the prevalence of nocturnal hypoventilation ranges between $10.3 \%$ and $61.2 \%{ }^{28}$. A previous study enrolled 232 adult patients with NMD based on eight different $\mathrm{NH}$ definitions (according to blood gas analysis and oxycapnography); daytime hypercapnia was detected in $38 \%$ of 232 patients and $\mathrm{NH}$ in $28 \%$ of those patients who were normocapnic during the daytime. The prevalence of SDB was found $36.8 \%$ in the muscular dystrophy group ${ }^{14}$. All of our patients were normocapnic during the daytime, and $\mathrm{NH}$ was detected in $33 \%(7 / 21)$ of them. Of those patients, $23.8 \%$ (5/21) showed nocturnal hypercarbia without concomitant nocturnal hypoxemia. We diagnosed $\mathrm{NH}$ in $25 \%$ of the muscular dystrophy group. Among those patients, two had isolated nocturnal hypercarbia and a patient had isolated nocturnal hypoxemia.

In a study on 221 pediatric patients, the $\mathrm{NH}$ prevalence was found $16 \%$ when the AASM criteria were used; moreover, its prevalence increased as the nocturnal hypercarbia index dropped. The prevalence of $\mathrm{NH}$ was found $31 \%$ when $\mathrm{PetCO}_{2}$ was greater than $50 \%$ and the nocturnal hypercarbia index was greater than $2 \%{ }^{15}$. We likewise detected $\mathrm{NH}$ in $9.5 \%$ of our patients when we based it on the AASM criteria and 33\% when we accepted a Nocturnal Hypercarbia Index of $2 \%$.

We admit that our study has some limitations. There is no unanimously accepted criterion for the definitions of nocturnal hypoxemia and hypercapnia. Without having any chance to assess the level of prognostic relevance, we arbitrarily chose three of the previously used criteria ${ }^{14-16}$. Although our study's prospective design is a favorable aspect, it has certain limitations such as the inclusion of a heterogeneous NMD population and a relatively small sample size. Furthermore, we lacked data on muscle strength (maximum inspiratory pressure and maximum expiratory pressure), cough efficiency (peak cough flow) and lung volumes in supine position due to lack of technical equipment and inadequate patient compliance, which resulted in spirometric pulmonary function testing being applied only in a certain proportion of the study population. As our sample size was small, the correlation between spirometric pulmonary tests and signs of abnormal nocturnal gas exchange may have been far from the actual figure. We could not compare PetCO $2 / \mathrm{SpO}_{2} / \mathrm{PaCO}_{2}$ monitoring with respiratory polygraphy or PSG to detect $\mathrm{NH}$ in patients with NMD. Instead, we aimed to determine if nocturnal hypercapnia existed in clinically asymptomatic NMD. We considered such approach would be an advantage for our study as signs of nocturnal hypoventilation are already more frequent than apneic events in patients with NMD.

\section{CONCLUSION}

We report for the first time the results of nocturnal PetCO $2 / \mathrm{SpO}_{2} / \mathrm{PaCO}_{2}$ monitoring in an NMD population of the youngest age group reported so far. Our study indicated that nocturnal $\mathrm{PetCO}_{2}$ and $\mathrm{PaCO}_{2}$ levels were statistically concordant with each other although the use of $\mathrm{PaCO}_{2}$ alone is not sufficient for early detection of $\mathrm{NH}$ in NMD. We believe that nocturnal capno-oximetry needs to be considered among scanning tools for the diagnosis of hypoventilation.

$\mathrm{NH}$ is a condition that is difficult to diagnose since it onsets with subtle symptoms. Considering its major impact on morbidity and mortality as well as its amenability to therapy, it is of importance to diagnose $\mathrm{NH}$. Our data indicate variations in the prevalence of $\mathrm{NH}$ depending on the definition and the methods used. As there is no verified nocturnal hypoventilation level associated with end-organ damage, it is warranted to consider more limited definitions for $\mathrm{NH}$, to conduct larger studies to reach an agreement on the best definition of hypoventilation and to update the existing consensus guidelines. 


\section{REFERENCES}

1. White JES, Drinnan MJ, Smithson AJ, Griffiths CJ, Gibson GJ. Respiratory muscle activity and oxygenation during sleep in patients with muscle weakness. Eur Respir J. 1995;8:807-14. [CrossRef]

2. Panitch HB. Respiratory implications of pediatric neuromuscular disease. Respir Care. 2017;62:826-48. [CrossRef]

3. Simonds AK. Chronichypoventilation and its management. Eur Respir Rev. 2013;22:325-32. [CrossRef]

4. Katz SL. Assessment of sleep-disordered breathing in pediatric neuromuscular diseases. Pediatrics. 2009; 123(Suppl 4):S222-5. [CrossRef]

5. Simonds AK. Domiciliary non-invasive ventilation in restrictive disorders and stable neuromuscular disease. In: Simonds AK, editor. Non-invasive Respiratory Support: A Practical Handbook. London, United Kingdom: Oxford University Press; 2001. p. 181-2.

6. Lissoni A, Aliverti A, Tzeng AC, Bach JR. Kinematic analysis of patients with spinal muscular atrophy during spontaneous breathing and mechanical ventilation. Am J Phys Med Rehabil. 1998;77:188-92. [CrossRef]

7. Beck SE, Marcus CL. Pediatric polysomnography. Sleep Med Clin. 2009;4:393-406. [CrossRef]

8. Grigg-Damberger MM. The AASM Scoring Manual four years later. J Clin Sleep Med. 2012;8:323-32. [CrossRef]

9. Kirk VG, Batuyong ED, Bohn SG. Transcutaneous carbondioxide monitoring and capnography during pediatric polysomnography. Sleep. 2006;29:1601-8. [CrossRef]

10. Richard N, Beydon N, Berdah L, Corvol H, Aubertin G, Taytard J. Nocturnal hypoventilation in down syndrome children with or without sleep apnea. Pediatr Pulmonol. 2020;55:1246-53. [CrossRef]

11. Kotterba S, Patzold T, Malin JP, Orth M, Rasche K. Respiratory monitoring in neuromuscular diseasecapnography as an additional tool. Clin Neurol Neurosurg. 2001;103:87-91. [CrossRef]

12. Miller MR, Crapo R, Hankinson J, et al. General considerations for lung function testing. Eur Respir J. 2005;26:153-61. [CrossRef]

13. Miller MR, Hankinson J, Brusasco V, et al. Standardisation of spirometry. EurRespir J. 2005;26:319-38. [CrossRef]

14. Ogna A, Quera Salva MA, Prigent H, et al. Nocturnal hypoventilation in neuromuscular disease: prevalence according to different definitions issued from the literature. Sleep Breath. 2016;20:575-81. [CrossRef]

15. Pautrat J, Khirani S, Boulé $M$, Ramirez A, Beydon N, Fauroux B. Carbon dioxide levels during polygraphy in children with sleep-disordered breathing. Sleep Breath. 2015;19:149-57. [CrossRef]

16. Berry RB, Quan SF, Abreu AR, et al. The AASM manual for the scoring of sleep and associated events: rules, terminology and technical specifications. Version 2.6. Darien, IL: American Academy of Sleep Medicine; 2020.

17. Won YH, Choi WA, Lee JW, Bach JR, Park J, Kang SW. Sleep transcutaneous vs. end-tidal $\mathrm{CO}_{2}$ monitoring for patients with neuromuscular disease. Am J Phys Med Rehabil. 2016;95:91-5. [CrossRef]

18. Takano Y, Sakamoto O, Kiyofuji C, Ito K. A comparison of the end-tidal $\mathrm{CO}_{2}$ measured by portable capnometer and the arterial $\mathrm{PCO}_{2}$ in spontaneously breathing patients. Respir Med. 2003;97:476-81. [CrossRef]

19. McDonald MJ, Montgomery VL, Cerrito PB, Parrish CJ, Boland KA, Sullivan JE. Comparison of end-tidal $\mathrm{CO}_{2}$ and $\mathrm{PaCO}_{2}$ in children receiving mechanical ventilation. Pediatr Crit Care Med. 2002;3:244-9. [CrossRef]

20. Eun MY, Seo WK. Monitoring of end-tidal $\mathrm{CO}_{2}$ : benefits to critically ill neurological patients. J Neurocrit Care. 2011;4:50-5. [CrossRef]

21. Hukins CA, Hillman DR. Day time predictors of sleep hypoventilation in Duchenne muscular dystrophy. Am J Respir Crit CareMed. 2000;161:166-70. [CrossRef]

22. Ragette R, Mellies U, Schwake C, Voit T, Teschler H. Patterns and predictors of sleep disordered breathing in primary myopathies. Thorax. 2002;57:724-8. [CrossRef]

23. Dohna-Schwake C, Ragette R, Mellies U, Straub V, Teschler H, Voit T. Respiratory function in congenital muscular dystrophy and limb girdle muscular dystrophy 2I. Neurology. 2004;62:513-4. [CrossRef]

24. Bersanini C, Khirani S, Ramirez A, et al. Nocturnal hypoxaemia and hypercapnia in children with neuromuscular disorders. Eur Respir J. 2012;39:1206-12. [CrossRef]

25. Fauroux B, Aubertin G, Clément A, Lofaso F, Bonora $M$. Which tests may predict the need for noninvasive ventilation in children with neuromuscular disease? Respir Med. 2009;103:574-81. [CrossRef]

26. Hull J. British Thoracic Society guideline for respiratory management of children with neuromuscular weakness: commentary. Thorax. 2012;67:654-5. [CrossRef]

27. Bayar B, Uygur F, Bayar K, Bek N, Yakut Y. Theshort -term effects of an exercise programme as an adjunct to an orthosis in neuromuscular scoliosis. Prosthet Orthot Int. 2004;28:273-7. [CrossRef]

28. Norwood F, de Visser M, Eymard B, Lochmüller H, Bushby $\mathrm{K}$. EFNS guideline on diagnosis and management of limb girdle muscular dystrophies. Eur J Neurol. 2007;14:130512. [CrossRef] 